\title{
El problema de la atribución de la eternidad a los modos finitos según Spinoza
}

\author{
GUILLERMO SIBILIA \\ Universidad de Buenos Aires \\ Consejo Nacional de Investigaciones Científicas y Técnicas
}

Resumen: La atribución de la eternidad a los modos finitos es una de las cuestiones más difíciles y polémicas de todo el pensamiento spinoziano. Nuestro objetivo en este artículo apunta a elucidar la doctrina oscura y polémica de la eternidad de la mente, o más precisamente del entendimiento humano. Esta meta incluye dos propósitos: por un lado, indagar los motivos que determinan el rechazo por parte de Spinoza de concebir la eternidad de la mente en los términos tradicionales de la inmortalidad del alma y, por el otro, comprender qué puede significar que, cuando muere el cuerpo, permanece algo de la mente que es eterno, tal como afirma Spinoza en la proposición 23 de la Quinta Parte.

Palabras clave: eternidad, inmortalidad, entendimiento, salvación. 


\title{
The Problem of the Attribution of Eternity to Finite Modes in Spinoza
}

\begin{abstract}
The attribution of eternity to finite modes is one of the most difficult and controversial issues of Spinozism. In this article we aim to elucidate the obscure and polemical doctrine of the eternity of the mind, or more precisely of the human understanding. Our objective includes two purposes: on the one hand, we aim to investigate the reasons that determine Spinoza's rejection of conceiving the eternity of the mind in the traditional terms of an immortality of the soul; and on the other, we aim to understand what it may mean that, when the body dies, something of the mind remains, as Spinoza affirms in EV, 23.
\end{abstract}

Key-words: eternity, immortality, understanding, salvation.

\section{Introducción}

Como puede reconocer cualquier lector, en la última parte entendimiento o de la libertad humana"- se distinguen claramente dos secciones, divididas por el escolio de la proposición 20. Allí Spinoza dice haber estudiado antes todo aquello que concierne a la "vida presente", esto es, a la duración de la mente y del cuerpo, así como también a todo aquello que puede la mente contra los afectos nocivos. A partir de ese momento, el filósofo holandés se propone demostrar una doctrina oscura y polémica: la eternidad de la mente, o más precisamente del entendimiento humano. Más allá de esa oscuridad, sea como fuere que comprendamos esa doctrina, algo es seguro: para Spinoza no se trata de un problema menor; por cierto, el solo hecho de que no haya cerrado la obra después de haber expuesto los

\footnotetext{
${ }^{1}$ En este artículo, utilizamos las siguientes abreviaciones para referirnos a las obras de Spinoza: $C M=$ Pensamientos metafísicos (seguido por el número de capítulo); $K V=$ Tratado breve (seguido por la parte, el capítulo y el parágrafo correspondiente); TIE = Tratado de la reforma del entendimiento (seguido por el número de parágrafo); TTP = Tratado teológico político (seguido por el número de capítulo); $T P=$ Tratado político (seguido por el número de capítulo y, en arábigos, por el número de parágrafo); $E$ = Ética (seguido por el número romano correspondiente a la parte de la obra, luego en números arábigos la proposición, y cuando corresponde, se señala si se trata de una demostración, un escolio, un corolario, un axioma, o una explicación). Utilizamos la edición canónica de Carl Gebhardt de las obras completas de Spinoza y, para todas las citas textuales, las traducciones al español de Atilano Domínguez.
} 
remedios contra los afectos es un testimonio irrefutable de ello.

Las cuestiones que son objeto de este artículo, relativas al problema de la atribución de la eternidad a los modos finitos, son sin dudas las más difíciles y polémicas de todo el pensamiento spinoziano. Es por eso que lo que sigue no pretende en absoluto resolver todas las dificultades que conlleva la teoría spinoziana de la eternidad de la mente. Nuestro interés es más bien otro: aceptando los puntos oscuros de la doctrina, queremos descubrir el sentido que acompaña y dirige ciertas afirmaciones de nuestro autor. Nuestro objetivo incluye dos propósitos: por un lado, indagar los motivos que determinan el rechazo por parte de Spinoza de concebir la eternidad de la mente en los términos tradicionales de una inmortalidad del alma y, por el otro, comprender qué puede significar que, cuando muere el cuerpo, "permanece algo" (aliquid remanet) de la mente que es eterno, tal como afirma Spinoza en la proposición 23 de la Quinta Parte de la Ética.

\section{Inmortalidad del alma versus eternidad de la mente}

omencemos por el hecho de que nuestro autor rechaza presentar
su doctrina de la eternidad de los modos finitos en la Ética en los términos de la inmortalidad del alma. ¿A qué obedece esa negativa en el discurso spinoziano? ¿Implica la ausencia casi total del concepto de immortalitas en este texto que la teoría de la inmortalidad del alma desaparece por completo? ¿No debemos pensar que se halla cubierta prudentemente en la doctrina de la eternidad de la mente? Esta parece ser la opinión de Wolfson, para quien la última parte de la obra póstuma no tiene otro propósito que demostrar, en la senda de la tradición judía de su formación juvenil, la inmortalidad del alma y refutar a quienes, como Uriel da Costa, la niegan (Wolfson 1934: 323 ss.). Sin embargo, si esto fuera así, deberíamos conceder que la aproximación de Spinoza a la cuestión que nos ocupa es únicamente el producto de su adhesión a ciertas doctrinas de la teología judía y cristiana que identifican la inmortalidad del alma con una forma de existencia "más allá", con una promesa futura. O bien, para defender de esa acusación a Spinoza, podríamos pensar que las últimas proposiciones de la Ética expresan simplemente la prudencia de nuestro autor, por lo cual su discurso final sería solo una concesión destinada a proteger la radical heterodoxia de la

\footnotetext{
${ }^{2}$ Nos preguntamos si desaparece por completo porque, como veremos, en los Pensamientos metafísicos, obra de juventud de Spinoza, se afirma explícitamente la inmortalidad del alma humana. (CM II, 12).
} 
obra. ¿Acaso debemos elegir alguna de esas vías? Como esperamos mostrar, creemos que ninguna de estas opciones puede sostenerse y que la posición de Spinoza es tan original como dificil de comprender.

Para dilucidar por qué no hay que asimilar la eternidad atribuida a los modos finitos con la inmortalidad del alma y para responder en los mismos términos que se plantea la cuestión en el desarrollo de la filosofia spinoziana, conviene resumir muy brevemente la forma en que aparece la doctrina en los textos que preceden a la Ética.

El mayor contraste con la obra póstuma lo encontramos en el único escrito que Spinoza publicó en vida con su nombre. En efecto, en los Pensamientos metafísicos, texto que no expresa tanto el pensamiento de nuestro autor cuanto su lectura y enmienda del cartesianismo y la escolástica, Spinoza afirma y demuestra la inmortalidad del alma. El filósofo holandés sigue a Descartes, para quien la inmortalidad supone una forma de subsistencia basada en el carácter sustancial de la mente, cuya conservación depende de la voluntad inmutable del Dios creador. En pocas líneas, nuestro autor reproduce prácticamente la misma doctrina: la mente es inmortal en virtud de las leyes de la naturaleza, es decir, a causa de los decretos inmutables establecidos por Dios; de lo que se sigue que una sustancia no puede ser destruida ni por sí misma ni por Dios; en consecuencia, la mente permanece o dura (más allá del cuerpo) gracias al concurso divino (CM II, 12). Es cierto que un poco antes, más precisamente en el capítulo 8 , Spinoza cuestiona indirectamente la noción cartesiana de voluntad divina (CM II, 8). Sin embargo, cuando analiza y demuestra la inmortalidad en el capítulo 12, sostiene -en línea con la filosofia cartesiana- que "quien tiene potestad para crear una cosa lo tiene también para destruirla", y que "Dios puede cambiar" las leyes que fijó (CM II, 12). En este sentido, podemos concluir que en los Pensamientos metafísicos, más allá de las críticas que realiza a muchos aspectos de su filosofia, Spinoza se mantiene a grandes rasgos fiel a Descartes. ${ }^{3}$

El otro escrito que Spinoza publicó en vida (aunque de forma anónima) no merece aquí mucho análisis. En todo caso, sirve a nuestro propósito más por lo que no dice que por aquello que afirma. En efecto, el Tratado teológico político, muy probablemente escrito unos años después de la publicación de la obra prologada por Meyer, no aborda de manera explícita la cuestión metafisica de la inmortalidad. De hecho, el término aparece una sola vez y lejos de cualquier significado técnico. Ahora bien, aunque esa ausencia -en un escrito cuyo interés primordial es estudiar la relación entre

${ }^{3}$ Jaquet 1997: 88 y Rousset 2000: 209.

GUILLERMO SIBILIA - El problema de la atribución de la eternidad a los modos finitos I 63-94 
religión y política — no nos sorprende demasiado, lo que sí llama nuestra atención, y debe por eso ser destacado, es que Spinoza omite la inmortalidad en su listado de los "dogmas de la fe universal" requeridos para asegurar la vida común en una ciudad, entre los que menciona ciertamente la creencia en un Dios que juzga y perdona (TTP XIV). El silencio de nuestro autor no puede ser sino deliberado y opera, en este sentido, como el signo de su rechazo a considerar el juicio y la sanción divinas como elementos vinculados a la subsistencia después de la muerte, es decir, a la inmortalidad. De esa manera, sin la necesidad de decirlo abiertamente, Spinoza excluye de la moral la preocupación por una vida en un más allá, algo que la Ética confirmará (Rousset 2000: 207).

Los otros textos que fueron publicados de manera póstuma son en cambio muy importantes para el tema que nos ocupa. ${ }^{4}$ Como sabemos, el Tratado de la reforma del entendimiento, que es anterior a los escritos que mencionamos antes, no estudia en ninguna parte el problema de la inmortalidad y se interesa por la determinación de un bien que "hiciera gozar [a quien lo descubriera] eternamente de una alegría continua y suprema" (TIE \1). Sin embargo, en la medida en que presenta una introducción a la filosofía y al modo de vida que conlleva, este opúsculo inconcluso ofrece elementos importantes para comprender la posición definitiva de Spinoza. En el parágrafo $\$ 89$, por ejemplo, donde nuestro autor indica el uso que podemos hacer de las palabras y aquel que deberíamos hacer para satisfacer las exigencias del entendimiento, sostiene que el término "inmortalidad" es un nombre negativo:

Añádase a ello que las palabras están formadas según el capricho y la comprensión del vulgo, y que, por tanto, no son más que signos de las cosas, tal como están en la imaginación y no en el entendimiento. Lo cual se ve en que a todas aquellas cosas que solo se hallan en el entendimiento y no en la imaginación les impusieron con frecuencia nombres negativos, tales como incorpóreo, infinito, etc.; y, además, muchas cosas que son afirmativas las expresan negativamente, y al revés, por ejemplo, increado, independiente,

\footnotetext{
${ }^{4}$ Omitimos en este resumen el Tratado político y la Correspondencia. El primero puesto que su abordaje del problema de la eternidad es tangencial y no se vincula con la cuestión específica de la inmortalidad del alma; solo se menciona la noción de "eterno" en relación con el poder de Dios o con las leyes que se siguen de su naturaleza (véase por ejemplo TP II, 2 y 8). En lo que concierne a la Correspondencia, omitimos el comentario de algunas cartas en las que -también tangencialmente- aparece el problema (sobre todo en el intercambio con Blyenbergh), porque no agregan mucho ni ofrecen una prueba formal de la inmortalidad.
} 
infinito, inmortal, etc. Es que sus contrarios los imaginamos mucho más fácilmente $[\ldots] .(T I E \ 89)$

La posición de Spinoza no deja lugar a dudas: puesto que la imaginación no puede concebir positivamente lo eterno, los seres finitos se lo representan como la negación de lo mortal. De esta manera, a partir de su contrario, se forja la noción de una inmortalidad como subsistencia, que termina prevaleciendo sobre el uso positivo y basado en el entendimiento de la de eternidad. Desde la perspectiva que abre este texto de juventud, entonces, la inmortalidad no es otra cosa que la versión imaginativa de una realidad o aspecto positivo de los seres finitos que solo el entendimiento puede aprehender.

Finalmente, debemos referirnos al Tratado breve, texto importante para nosotros porque -a diferencia de los Pensamientos metafisicos- rechaza de manera explícita la teoría de la creación continua y, en consecuencia, no admite ninguna distancia esencial entre Dios y sus efectos. Al contrario, afirma la inmanencia de las cosas en Dios y, sobre todo, su "unión" (por ejemplo KV II, $26 \$ 9)$. Ahora bien, pareciera que en esta obra Spinoza no se atiene a su propia advertencia del Tratado de la reforma del entendimiento, ya que aparentemente utiliza sin distinguir los conceptos de inmortal y eterno para caracterizar el estado inalterable del entendimiento humano que se une a Dios. En efecto, en la nota 15 del Prefacio de la segunda parte dice que el alma es un modo en la sustancia pensante, que al unirse con sustancias que son siempre las mismas, ha podido hacerse a sí misma eterna ( $K V$ II, Prefacio). Pero más adelante, demuestra la indestructibilidad del alma en un capítulo al que titula: "De la inmortalidad del alma" (KV II, 23).

Si el Tratado breve es posterior al Tratado de la reforma del entendimiento, ¿cómo debemos comprender esa utilización de los términos? ¿Son aquí nociones intercambiables? Para comenzar a dar una respuesta, debemos destacar dos cosas: en primer lugar, que la obra que comentamos fue el resultado de sucesivas redacciones. De hecho, como sabemos, existen dos manuscritos en holandés del Tratado breve y ninguno fue escrito por Spinoza. En segundo lugar, hay que subrayar el hecho de que todas las obras que de hecho fueron escritas por el filósofo holandés distinguen sistemáticamente los conceptos de inmortalidad y eternidad e imputan el primero a una concepción imaginativa de lo eterno. Por lo tanto, quizás tiene razón Jaquet al sostener que el deslizamiento de un término a otro no es en absoluto accidental sino deliberado y repetido (Jaquet 1997: 80 ss.). En efecto, la intérprete muestra cómo, inmediatamente después de haber aclarado la naturaleza de la unión con Dios y de afirmar que de ella se sigue "una estabilidad eterna e inmutable" (KV II, 22 \$7), Spinoza sostiene que "si 
observamos con atención qué es el alma y de dónde provienen su cambio y su duración, veremos fácilmente si es mortal o inmortal” (KV II, $23 \$ 1$ ). Y agrega que en el último capítulo del Tratado breve, el filósofo holandés deduce la eternidad del entendimiento a partir de la imposibilidad de que sea destruido por una causa interior o exterior y de la inmutabilidad del Dios eterno que produce ese entendimiento ( $K V$ II, 26 8). La argumentación de la intérprete puede resumirse de la siguiente manera. Según ella, en el capítulo titulado "De la inmortalidad del alma", nuestro autor se limita únicamente a mostrar que la temporalidad del alma depende del objeto al que está unido: si se une a una cosa que cambia y muere, ella también debe perecer; si se une a una cosa inmutable e imperecedera, "deberá, por el contrario, permanecer inmutable" (KV II, 23 1-2). La inmortalidad es aquí sinónimo de indestructibilidad e inmutabilidad y caracteriza el estado de un ser que no dispone el poder para comenzar a existir ni para dejar de hacerlo y que depende de una causa imperecedera e inmutable. Ahora bien, en el capítulo 23 no se juzga la naturaleza de esa inmutabilidad. Es por eso que la demostración de la eternidad del entendimiento requiere algo más que la evidencia de su carácter inmortal. Según el capítulo 26, el último de este escrito, hacen falta tres condiciones: primero, la ausencia de una causa interna de destrucción; en segundo lugar, la ausencia de una causa externa que pueda destruir el entendimiento; finalmente, la presencia de una causa interior (o inmanente) eterna. Si no se cumple la tercera cláusula, el entendimiento puede gozar a lo sumo de una sempiternidad, pero no puede decirse que es eterno. Por eso, Jaquet concluye que en el Tratado breve, la "inmortalidad es indiscutiblemente una noción negativa e incompleta porque solo indica la ausencia de una causa de destrucción sin precisar la naturaleza de la inmutabilidad" (Jaquet 1997: 86). De esta manera, aunque el título del capítulo 23 ("De la inmortalidad del alma") pueda inducir a equívocos, vemos que el interés de Spinoza en la segunda parte de la obra es establecer la eternidad del entendimiento. En este sentido, la inmortalidad es solo una etapa en la demostración de esa eternidad y no debe confundirse con ella. En definitiva, a pesar de las apariencias, los términos nos son utilizados por Spinoza como sinónimos, no son equivalentes ni intercambiables.

Ahora bien, aunque para nuestro autor no son nociones idénticas, hay que reconocer que la explicación de la eternidad de la mente (o del entendimiento verdadero) es en este escrito oscura, en la medida en que se fundamenta en una "unión" con la "sustancia pensante" (o con Dios) que la filosofía madura de Spinoza rechazará por completo. Sin embargo, sea como fuere que interpretemos el Tratado breve, algo es seguro: el estado inmutable que alcanza por sí misma la mente uniéndose a Dios, no es de ninguna manera una inmortalidad personal. Es decir, no se trata de una vida futura 
post mortem, en la que un individuo encontraría la felicidad suprema. Este rechazo representa la posición de Spinoza incluso en su obra más sistemática, la Ética. Pero, a diferencia del Tratado breve, nuestro autor ya no considera necesario recurrir a la noción de inmortalidad para probar la eternidad de la mente o de una parte suya. De hecho, en este texto, el término immortalitas no figura ni una sola vez: no es empleado nunca para caracterizar la naturaleza de Dios, ni para explicar la de la "existencia" que pertenece a la mente sin relación con la duración del cuerpo. Spinoza utiliza solo una vez el adjetivo "inmortal" en la Quinta Parte, más precisamente en el escolio de $E \mathrm{~V}, 41$. No obstante, el término aparece en el contexto de la descripción que hace nuestro autor de la convicción común del vulgo, y no para expresar su propio pensamiento. En efecto, Spinoza critica la persuasión del vulgo y de todos aquellos que piensan que una vida virtuosa solo vale la pena si conduce a una recompensa en un más allá ( $E \mathrm{~V}, 41$ escolio). Ahora bien, si hay algo que caracteriza de manera constante su filosofia práctica es la oposición a cualquier moral que prescriba el deber de la renuncia por sobre el esfuerzo de la liberación. Resulta evidente, entonces, que nuestro autor quiere subrayar allí la importancia de la virtud en esta vida, sin atar los comportamientos de un ánimo firme a la esperanza de premios o al temor a castigos, y que, por lo tanto, no pretende equiparar la eternidad con la inmortalidad.

Se podría objetar esto recurriendo al escolio de la proposición 20 de la Quinta Parte, en donde Spinoza dice que, después de haber explicado "todo lo que se refiere a la vida presente", pasará a estudiar "las cosas que pertenecen a la duración de la mente sin relación con el cuerpo" (E V, 20 escolio). Puesto que la inmortalidad se refiere, como vimos, siempre a alguna forma de duración o subsistencia, el filósofo holandés parecería avalar indirectamente la equiparación entre la eternidad y una existencia post mortem. Sin embargo, como recuerdan Prelorentzos y Jaquet, debemos tener en cuenta que no utiliza allí el término "duración" en su sentido técnico, tal como fue definido en la Segunda Parte, sino en uno genérico, conforme al uso de la escolástica. Esto significa que en ese escolio bisagra nuestro autor no prejuzga la naturaleza de la existencia de la mente sin relación con el cuerpo antes de demostrar su eternidad. ${ }^{5}$ Por otro lado, tampoco debemos olvidar que Spinoza se toma el cuidado en la Quinta Parte de la Ética de distinguir dos modalidades diferentes de actualidad y de aprehensión de las cosas $(E \mathrm{~V}$, 29 escolio). La duración (que supone una determinación espacio-temporal) y la eternidad (que no se puede explicar por la duración o por el tiempo) son

\footnotetext{
${ }^{5}$ Prelorentzos 1992: 417, nota 3; Jaquet 1997: 139.
} 
siempre conceptos que definen propiedades irreductibles o, mejor, formas distintas de la actualidad o ser de una misma cosa. En este sentido, y en virtud de esa irreductibilidad, no puede pensarse que la eternidad de la mente -que será demostrada recién a partir de $E \mathrm{~V}, 22$ - es una prolongación de la existencia actual presente. Al contrario, debe siempre diferenciarse de su duración hic et nunc. ${ }^{6}$

Para Spinoza, no hay entonces una inmortalidad personal, una supervivencia post mortem de la identidad subjetiva, tal como la imaginación y la memoria la representan e incluso tal como contribuyen a configurarla. La eternidad no está en una existencia previa que podríamos recordar ni en una existencia posterior a la que accederíamos por gracia divina, conservando las trazas singulares del yo que define la imaginación y la memoria. Spinoza expresa esto claramente en el escolio de $E \mathrm{~V}, 23$, que comentaremos más adelante, y que puede interpretarse como una respuesta polémica a la tradicional (y vulgar) equiparación de lo eterno con lo inmortal o con la permanencia de la persona que fuimos, mientras tuvimos una vida presente. Como dice Spinoza: "No puede suceder [...] que recordemos haber existido antes del cuerpo, puesto que no puede existir de ello ningún vestigio en el cuerpo, ni puede la eternidad definirse por el tiempo ni tener con él relación alguna" ( $E$ V, 23 escolio).

Se objetará que nuestro autor dice en la proposición que "permanece algo" (aliquid remanet) de la mente que es eterno (EV, 23). Sin embargo, Spinoza puede utilizar de manera legítima esa expresión porque existen dos maneras de concebir las cosas: sub specie aeternitatis y sub specie durationis. Esto significa que el verbo remanet refiere a una subsistencia luego de la muerte únicamente si se conciben las cosas en relación con un tiempo y un lugar determinados; por el contrario, si se las considera como contenidas en Dios y siguiéndose de la necesidad de su naturaleza, esto es, como efectos de su libre necesidad, no debe interpretarse que la "permanencia" indica una existencia cronológica o que el verbo correspondiente tiene una connotación temporal. Por lo tanto, estamos de acuerdo con Jaquet cuando afirma que Spinoza no temporaliza nunca la eternidad (Jaquet 1997: 135-136). Desde este punto de vista, entonces, la creencia en una inmortalidad personal es solo el resultado de una confusión, es la consecuencia del intento de comprender a través de la sola imaginación algo que solo puede ser entendido. Spinoza confirma esto un poco más adelante:

\footnotetext{
${ }^{6}$ Sin embargo, como veremos más adelante, es "durante" la existencia actual de los seres humanos que es posible, para unos pocos, ejercer y desarrollar la aptitud de comprender qué es para Spinoza ese "algo" (aliquid) eterno en algunos seres humanos.
} 
Si atendemos a la opinión común de los hombres, veremos que ellos son sin duda conscientes de la eternidad de su mente; pero que la confunden con la duración y la atribuyen a la imaginación, o sea, a la memoria que creen que permanece después de la muerte. ( $E$ V, 34 escolio).

En definitiva, podemos concluir que también en la Ética Spinoza rechaza tanto la doctrina tradicional de la inmortalidad del alma como también la necesidad de recurrir a esa expresión para probar la eternidad de una parte de la mente, esto es, de la idea que expresa la esencia del cuerpo sub specie aeternitatis. En este sentido, el abandono del concepto immortalitas en esa obra no es el resultado de un accidente, sino que se debe a una modificación profunda de la doctrina, tanto respecto de los Pensamientos metafísicos como del Tratado breve. Ahora bien, luego de este recorrido, constatamos que no alcanza con distinguir la inmortalidad de la eternidad y sostener que para Spinoza no son términos intercambiables. Para nuestro propósito, es necesario ir más lejos y analizar el estatus ontológico de la eternidad atribuida por Spinoza de manera explícita y positiva a los modos finitos en las últimas proposiciones de la Ética.

\section{Los modos finitos, la eternidad y la salvación humana}

Tos problemas que movilizan este apartado y que intentaremos elu-

Lidar aquí pueden resumirse en las siguientes preguntas. ¿Cómo podemos comprender el sentido de las últimas proposiciones de la Ética? ¿Cómo se explica allí la atribución de la eternidad a los modos finitos y, más precisamente, a los seres humanos? Si, como hemos visto, Spinoza rechaza de manera constante la concepción tradicional de la inmortalidad personal y si no temporaliza nunca la eternidad, ¿cómo debemos interpretar uno de los pasajes más citados de la Ética, donde afirma que "sentimos y experimentamos que nosotros somos eternos" (sentimus experimunque nos aeternos esse) ( $E$ V, 23 escolio)? ¿Cómo se relaciona esta "experiencia" con la concepción sub specie aeternitatis?

Antes de intentar una respuesta, permítasenos subrayar tres cosas que consideramos indispensables para una comprensión adecuada del problema que nos ocupa. Por un lado, como venimos de ver, la reflexión que comienza en la proposición 21 de la Quinta Parte no se refiere a una prometida vida futura. No hay inmortalidad (o duración más allá de la muerte) sino desde la perspectiva de la imaginación que confunde la eternidad con la existencia actual determinada. Spinoza no quiere decir que -a partir de EV, 22- se re- 
ferirá a la existencia de los seres humanos después de la muerte; quiere decir que, con la meditación acerca de los remedios contra los afectos nocivos, ha finalizado su presentación de lo que concierne a la vida de los hombres en cuanto existencia actual presente. ¿Significa esto que hay otra vida "más allá"? De ninguna manera, pero sí hay otra manera de vivir, que se vincula con la potencia intrínseca que caracteriza a la mente (la potencia de pensar y conocer) y que constituye el fundamento definitivo del proyecto ético spinozista que reduce la salvación humana o beatitud a la liberación.

Por otro lado, es innegable que la Ética extiende el concepto de eternidad más allá del confin que le asignaba el discurso de los Pensamientos metafísicos, cuando hacía de ella una propiedad exclusiva de Dios. En efecto, la segunda sección de la Quinta Parte, muchas veces con un lenguaje bastante ambiguo, explica que la eternidad se comunica a todas las cosas que se siguen de la potencia de Dios e incluso a los seres humanos, o más precisamente, a su entendimiento adecuado y a una "parte" de su mente. La obra póstuma rompe entonces con el esquema cartesiano de los Pensamientos metafisicos, en el que Dios no comunica a sus criaturas esa propiedad suya.

Finalmente, para comprender cómo procede la atribución de la eternidad a cierto aspecto de ciertos modos finitos en la Ética, hay que tener en cuenta que de acuerdo con la ontología de Spinoza los modos finitos son actuales en dos sentidos: tienen una existencia actual presente o duración, que designa su existencia determinada por causas exteriores, y también tienen una actualidad que corresponde a su ser formal, al hecho de que sus esencias formales están contenidas eternamente en los atributos divinos del que son solo una expresión parcial. Como se desprende de E I, 16, esto significa que son todos en cierta medida eternos, cuando se los considera no a partir de su determinación extrínseca y como cosas vinculadas a una dimensión espacio-temporal, sino como esencias actuales que se siguen -más tarde o más temprano, pero de manera absolutamente necesaria- de la naturaleza divina. Desde esta perspectiva, todas las cosas particulares son efectos absolutamente necesarios de una trama infinita, de una producción eterna e intemporal. ${ }^{7}$ En el mismo sentido debe leerse la proposición 45 de la Segunda Parte, en la cual Spinoza dice que las "cosas singulares" que existen en acto implican necesariamente la esencia eterna e infinita de Dios $(E$

\footnotetext{
${ }^{7}$ Subrayemos aquí la restricción que impone la expresión "en cierta medida": Spinoza no dice nunca que las esencias son eternas, sino que son "verdades eternas" o que son "cosas" que Dios concibe con verdad. La única vez en toda su obra que dice que las esencias de las cosas son eternas, lo hace con reticencia y a través del discurso de la creación que está criticando (CM II, 1).
} 
II, 45). Incluso, para evitar cualquier confusión, en el escolio que añade a esa proposición, nuestro autor agrega que por "existencia actual" no se refiere a la duración (que depende de causas externas), sino a "la naturaleza misma de la existencia, que se atribuye a las cosas singulares por el hecho de que de la necesidad eterna de Dios proceden infinitas cosas en infinitos modos", es decir, "la existencia misma de las cosas singulares, en cuanto son en Dios" (E II, 45 escolio; subrayado nuestro). Para Spinoza, esto significa que las esencias de las cosas no son entes posibles que Dios decide crear voluntaria y contingentemente en algún momento; por el contrario, son siempre efectos que se siguen necesariamente de las leyes de su naturaleza infinita, de la misma forma que de la naturaleza del triángulo se sigue siempre que sus tres ángulos son iguales a dos rectos (véase al respecto $E$ I, 17 escolio).

En conformidad con estos puntos, podemos diferenciar entonces dos perspectivas a partir de las cuales Spinoza atribuye la eternidad a la mente humana en la ontología de la Quinta Parte de la Ética. Una concierne a lo que Matheron ha llamado la "eternidad en sí", esto es, a la eternidad que pertenece a todas las cosas singulares en su esencia, en la medida en que hay de ellas una idea en el entendimiento de Dios; la otra, corresponde a la "eternidad para sí", es decir, a la mayor o menor conciencia y conocimiento de esa propiedad, que ya no es exclusividad de Dios, sino que se le atribuye legítimamente a cierto aspecto de los modos finitos que se vincula con la salvación de los seres humanos (Matheron 2011: 693-705).

\section{La "eternidad en si": lo eterno como propiedad común de todas las mentes}

工 a primera perspectiva, que se desarrolla a lo largo de las la eternidad de la mente. Spinoza comienza por el segundo punto, para desestimar de entrada cualquier confusión de esa propiedad que, como dirá, "pertenece a la esencia de la mente" con lo que tradicional y vulgarmente se llama inmortalidad. En este sentido, en EV, 21 sostiene que la "mente no puede imaginar nada ni recordar las cosas pasadas sino mientras dura el cuerpo (nisi durante corpore)". Para demostrar esto, nuestro autor se apoya de manera exclusiva en determinados pasajes de la Segunda Parte de la Ética. Primero evoca el célebre corolario de la proposición 8 para afirmar que la mente expresa la existencia actual de su cuerpo y que, por consiguiente, concibe como actuales las afecciones corporales únicamente mientras dura el cuerpo ( $E \mathrm{~V}, 21$ demostración). Esta referencia se repetirá en la demostración de $E \mathrm{~V}, 23$, lo cual revela que ese corolario es fundamental para comprender 
ciertos aspectos importantes de la doctrina de la eternidad de la mente.

El filósofo holandés establece allí una distinción entre dos tipos de actualidad de las cosas singulares, ya sea que se las considere solamente en cuanto están "comprendidas" (es decir, contenidas) en los atributos, o bien se las conciba en cuanto que existen partes extra partes, es decir, no solo comprendidas en los atributos, sino además en cuanto que se dice que duran (E II, 8 corolario). En otras palabras, podemos considerar las cosas naturales como contenidas en acto y eternamente en los atributos de Dios, por un lado, y como cosas que duran y se esfuerzan por perseverar en la existencia, es decir, con una presencia (también en acto) en el tiempo, por el otro. La naturaleza de esta segunda manera de existir no conlleva muchas dificultades; se trata de la existencia actual presente, que depende de la determinación de causas externas y finitas. Más dificil, en cambio, es la primera; no solo porque Spinoza no nos dice en ese corolario en qué consiste, sino porque no hace referencia a ella hasta este momento de la deducción.

Sin embargo, el filósofo holandés nos suministra ciertos indicios importantes para entender la utilización de ese corolario en la sección final de la Ética. En primer lugar, nos advierte acerca del modo como afecta la llamada doctrina del "paralelismo" al problema que nos ocupa. Reenviando al escolio de $E$ II, 7, sostiene que a la inclusión de una esencia formal en un atributo de Dios corresponde la "existencia" de su idea como comprendida en la idea de Dios y no simplemente como contenida en el atributo pensamiento $(E$ II, 8 corolario y escolio). Es cierto que eso supone que -en cuanto tiene o es una esencia formal- también está contenida en ese atributo, pues todas las ideas son "en sí mismas" modos del atributo pensamiento. Ahora bien, lo que importa señalar aquí es que esas ideas están también comprendidas en el intelecto infinito (esto es, en el modo infinito inmediato de ese mismo atributo), justamente porque es el punto que Spinoza va a desarrollar en la Quinta Parte. En segundo lugar, aunque no nos diga positivamente en qué consiste la existencia de las cosas en cuanto contenidas en los atributos divinos, el corolario sí precisa de qué modalidad de la existencia se distingue, a saber: de la existencia actual presente o duración. En efecto, como ya indicamos, para las cosas singulares en general (incluidas las ideas) "existir" en cuanto que están solamente contenidas en los atributos no es existir en un tiempo y lugar determinados. Quizás hasta podría decirse que no es "existir" tout court, y que, por consiguiente, "estar contenidas" en los atributos no significa otra cosa que tener una esencia que se sigue necesariamente de la esencia divina.

Ahora bien, esta correspondencia vale también para las ideas de las cosas que existen en acto, que según Spinoza "implican" una existencia "por la que se dice que duran" (E II, 8 corolario). Esto significa, en otras palabras, 
que las ideas que Dios tiene o que están en el entendimiento infinito -y que ya expresan objetivamente tanto la existencia de la cosa (un cuerpo) como aquello que le sucede (sus afecciones)- deben asimismo estar sujetas a la duración en cuanto a su realidad formal. La mente de Pablo por caso -es decir, la idea del cuerpo de Pablo- tiene una existencia actual, hic et nunc. ¿Pero qué pasa cuando una idea -que está en Dios- no expresa objetivamente la existencia de una cosa que dura? ¿Qué pasa, por ejemplo, cuando desaparece el cuerpo de Pablo o cuando no consideramos el objeto de la idea-mente de Pablo? ¿Acaso hay que decir que esa idea no es nada, que es un puro posible en el intelecto infinito? ¿O debemos considerar que expresa siempre "algo" que no depende de la duración y que, por lo tanto, es una verdad eterna? Spinoza es riguroso en la respuesta. Puesto que de la naturaleza divina se sigue necesaria y eternamente "todo lo que puede caer bajo un entendimiento infinito", esto es, todo lo que "debe" existir (E I, 16), resulta claro que, si en Dios hay algo que expresa una verdad eterna, ese "algo" es independiente de cualquier consideración temporal.

Por lo tanto, si Spinoza evoca en EV, 21 el corolario de E II, 8, no lo hace para afirmar una supuesta existencia en la eternidad de cosas que ya no existen más o que todavía lo hacen en la duración. Es cierto que Spinoza subraya el hecho de que las cosas singulares tienen una doble actualidad; pero eso no significa que, cuando no existen en acto, “existen" y están esperando en algún cielo de las formas su producción por una potencia infinita (Dios), o bien que, cuando su cuerpo muere, comienzan a existir en la eternidad por gracia divina. En este sentido, el acento puesto por el filósofo holandés en la modalidad actual de las esencias contenidas en los atributos (y de sus ideas en la idea infinita), tiene el propósito de aclarar un aspecto importante relativo a la eternidad de la mente humana (o mejor dicho del entendimiento), a saber: que es una propiedad de su esencia y que se relaciona con la manera como se vive hic et nunc la eternidad, pero no con la postulación de alguna esfera o dimensión irreductible y separada de la existencia de las cosas. El corolario no es una meditación acerca de lo que sucederá después de la muerte o de lo que habría sucedido antes de la existencia en la duración, sino acerca de aquello que sucede y puede suceder mientras el modo finito existe.

Comprendemos entonces el primer movimiento deductivo de la demostración de EV 21, donde -como ya señalamos- Spinoza afirma que la mente expresa la existencia actual de su cuerpo y concibe como actuales las afecciones corporales, únicamente mientras dura el cuerpo (nisi durante corpore). De acuerdo con lo anterior, esto significa que la mente es -en su ser actual- la idea que Dios tiene de nuestro cuerpo existente en acto, es decir, la idea que expresa objetivamente la existencia actual de nuestro cuerpo y de todo lo que le sucede. Ahora bien, como vimos, esa idea tiene (según 
E II, 8 corolario) una existencia temporal y expresa objetivamente la existencia actual de su ideatum solo en la medida en que este último existe de manera actual en la duración. Por lo tanto, aunque Spinoza deja ciertamente abierta aquí la cuestión de si la mente puede o no expresar "otra cosa", establece ya algo importante: cuando un cuerpo deja de durar, la mente que es su idea no puede de ninguna manera expresar la existencia actual de su cuerpo, porque eso implicaría ipso facto que Dios concibe algo falso; esto es, implicaría que hay en el entendimiento infinito una idea (una mente) que expresa objetivamente la existencia actual de un cuerpo que sin embargo no existe en acto.

La demostración de EV, 21 finaliza con las consecuencias que se desprenden de todo lo anterior:

Y, por tanto (et consequenter) (por E II, 26), [la mente] no concibe ningún cuerpo como actualmente existente sino mientras dura su propio cuerpo.Y por lo mismo, no puede imaginar nada (ver la definición de la imaginación en $E$ II, 17 escolio) ni recordar las cosas pasadas sino mientras dura el cuerpo (ver la definición de la memoria en E II, 18 escolio) (EV, 21 demostración).

Puesto que tiene una existencia actual presente únicamente mientras su objeto tiene una existencia actual presente y, por eso, solo percibe los cuerpos exteriores como existentes en acto -aquí y ahora- a través de las afecciones de su cuerpo, no puede suceder que la mente humana conciba un cuerpo cualquiera, cuando el cuerpo del que ella es la idea ha dejado de existir actualmente. Por el mismo motivo, no puede imaginar nada ni recordar las cosas pasadas que la modificaron sino mientras dura su cuerpo. En este sentido, incluso antes de explicar si la mente es destruida "totalmente" con el cuerpo, Spinoza establece que no subsiste nada de ella relacionado con la imaginación y con la memoria.

Ahora bien, esa manera de pensar y concebir las cosas como actuales en un espacio y tiempo determinados y en función de la forma en que afectan al cuerpo, si bien es la más común, no es la única. La locución adverbial con la que se abre la proposición 22 (que explicita las reglas que permiten sustraer la mente y su funcionamiento de la lógica de la duración) evidencia precisamente esto: "Sin embargo, en Dios (In deo tamen) existe necesariamente una idea que expresa la esencia de este o aquel cuerpo humano sub specie aeternitatis" $(E V, 22)$.

¿Qué significa esta extraña afirmación y cómo se relaciona con la mente humana y el cuerpo del que aquella es la idea? Spinoza demuestra esa proposición recordando primero que Dios (o el ser absolutamente infinito) es causa tanto de la existencia de los cuerpos en la duración como de su 
esencia y que, por lo tanto, esta última "debe concebirse necesariamente" por su esencia infinita $\left(E V, 22\right.$ demostración). ${ }^{8}$ En seguida, el filósofo holandés subraya el principio de necesidad que caracteriza la producción eterna de lo real, de la que Dios tiene una idea. Para ello, remite a dos proposiciones muy importantes: la 16 del De Deo, y la 3 del De origine et natura mentis (EV, 22 demostración). Como sabemos, según la primera, de la naturaleza divina deben seguirse infinitas cosas en infinitos modos, es decir, todo lo que puede caer bajo un entendimiento infinito. De acuerdo con la segunda, en Dios se da necesariamente una idea, tanto de su esencia como de todas las cosas que se siguen necesariamente de ella. El razonamiento de Spinoza en la proposición 22 puede entonces resumirse de la siguiente forma: puesto que Dios es causa de la esencia y de la existencia de todas las cosas, debe ser causa de la esencia singular de todos los cuerpos.Y ello de acuerdo a una necesidad independiente de cualquier consideración temporal. Esto significa que las "cosas" (o mejor dicho, las esencias de las cosas) se siguen de la esencia de Dios con una necesidad absoluta y eterna. Por lo tanto, puesto que todas las esencias según la proposición 16- se siguen de la naturaleza divina de una manera absolutamente necesaria, también la esencia singular "de este o aquel cuerpo humano" se concibe como una verdad eterna, en cuanto es una consecuencia de la esencia de Dios, es decir, en cuanto es una expresión particular del atributo extensión del que hay una idea en Dios. Pero simultáneamente, en virtud de la correspondencia de los atributos, lo anterior implica que la idea por la cual el ser perfectísimo -en su entendimiento infinito- concibe esa esencia es asimismo una verdad eterna.

En definitiva, la proposición 22 afirma que "en Dios" (in Deo) -esto es, en el entendimiento infinito- las ideas de las cosas se siguen de manera absolutamente necesaria, de acuerdo con una ley de producción que no está sometida a la duración o al tiempo (Macherey 1994: 124). Para lo que nos interesa aquí, esto significa que, consideradas sub specie aeternitatis como afecciones de los atributos divinos, tal como se producen en y por Dios (es decir, como expresiones de su potencia infinita), las cosas singulares y también sus ideas son en cierta medida eternas. O para ser más precisos, corresponden a verdades eternas.

La proposición 23 cierra esta primera perspectiva a partir de la cual es estudiada la eternidad de la mente. La fórmula, cuya ambigüedad es causa de

\footnotetext{
${ }^{8}$ Lo que la demostración afirma respecto del "cuerpo humano" vale, como veremos, para toda cosa singular en la medida en que se expresa en modos que se siguen necesariamente de los atributos divinos; es decir, vale para la esencia de los cuerpos, de las ideas, y de la de cualquier otro modo de los infinitos atributos que no conocemos.
} 
muchas dificultades en el spinozismo, dice lo siguiente: "La mente humana no puede ser totalmente destruida con el cuerpo, sino que permanece algo de ella que es eterno" $(E \mathrm{~V}, 23)$. ¿Qué significa que la mente humana no puede ser "totalmente" destruida con el cuerpo? ¿Acaso "permanece" una "parte" de ella luego de la muerte? Si, como vimos, no hay inmortalidad personal, cuando muere Pablo ¿no debería su mente desaparecer por completo? Como hicimos antes, detengámonos en la demostración para dar una respuesta a estas preguntas. Apoyándose en lo que acaba de ser afirmado antes y en dos pasajes centrales de la Segunda Parte (E II, 13 y E II, 8 corolario), Spinoza sostiene que el concepto o idea que está en Dios y que expresa la esencia de este o aquel cuerpo sub specie aeternitatis es necesariamente algo que "pertenece" a la esencia de esta o aquella mente humana correspondiente ( $E \mathrm{~V}, 23$ demostración). Esto significa que, en tanto es la idea de una esencia, la mente humana tiene también una esencia y, en cuanto tal, debe ser concebida por Dios como una verdad eterna.

Sin embargo, es importante subrayar que, para demostrar esto, Spinoza se apoya en la proposición 13 de la Segunda Parte. Como sabemos, en ella se explica que el único objeto de la idea que constituye la mente es el cuerpo, es decir, un modo de la extensión que existe en acto, y ninguna otra cosa $(E$ II, 13). En otras palabras, nos enseña que la mente es ante todo la idea de un cuerpo existente en acto. Ahora bien, esa actualidad puede remitir, como ya señalamos, a una existencia espacio-temporal o bien al hecho de que ese cuerpo se sigue necesariamente de Dios, puesto que es una expresión particular de uno de sus infinitos atributos. Precisamente a esto apunta el corolario de la proposición 8 de la Segunda Parte, que figura en esta demostración ( $E \mathrm{~V}, 23$ demostración). ${ }^{9}$ En este sentido, comprendemos que la referencia a la proposición 13 está plenamente justificada: para nuestro autor, la definición de la mente (como idea del cuerpo) sigue siendo válida; sim-

\footnotetext{
${ }^{9}$ Como ya dijimos, Spinoza se pregunta en $E$ II, 8 corolario qué pasa con las esencias de las cosas y con sus ideas cuando no existen en la duración. La respuesta, que ahora nos resulta más clara, puede resumirse así: las esencias de las cosas singulares (o, como dice Spinoza, las esencias formales) y las ideas de esas esencias (o esencias objetivas de las cosas) son expresiones eternas de las cosas que se siguen de los atributos divinos. Son, por así decir, aspectos independientes de la existencia determinada espacio-temporalmente. Por supuesto, esto no significa que las esencias de las cosas y las ideas de esas esencias sean absolutamente independientes: no son causa de sí, sino de Dios bajo los atributos del que son una expresión particular. En este sentido, si bien las esencias son un aspecto independiente de la determinación espacio-temporal de la cosa de la que son la esencia, esa determinación solo es inteligible a la luz de la esencia eterna divina, es decir del ser absolutamente infinito que tiene in se todo lo que produce.
} 
plemente sucede que sus términos son repensados aquí en función de la distinción entre la existencia del cuerpo y su esencia (Macherey 1994:126). Por lo tanto, la conclusión es siempre la misma: sea que consideremos la mente humana como la idea de una existencia en acto o bien como la idea de una esencia que nunca es un mero posible, se mantiene una correspondencia estricta entre esta idea y su objeto que es el cuerpo, considerado ora en su existencia actual, ora en su esencia, también actual. Subrayemos, sin embargo, que no se trata aquí de la idea que nosotros tenemos, sino de la que Dios tiene. Es decir, se trata de la mente como idea de Dios, en cuanto es un modo de la sustancia (genitivo subjetivo) y en cuanto es asimismo una idea que tiene por objeto un modo de Dios, un cuerpo (genitivo objetivo).

En este contexto, ¿qué significa que algo le "pertenece" a la esencia de la mente? La expresión "ad essentiam mentis humanae pertinet" no puede sino reenviarnos a $E$ II, definición 2. En efecto, Spinoza explica allí que pertenece a la esencia de una cosa aquello que, si se da, se pone necesariamente la cosa, y que, si se quita, se quita necesariamente la cosa; o sea, aquello sin lo cual la cosa no puede ser concebida y, a la inversa, aquello que sin la cosa no puede ser ni ser concebido (E II, definición 2). De acuerdo con esa definición, entonces, existe una relación de reciprocidad entre la esencia de una cosa y sus propiedades constitutivas. En este sentido, decir que una característica A pertenece a la esencia de una cosa $\mathrm{X}$ equivale a decir que $\mathrm{X}$ comporta necesariamente A (o sea, que es imposible concebir que esa cosa no tenga esa característica); y recíprocamente, que toda cosa que comporta o tiene la característica A es necesariamente X (es decir, que es imposible concebir que sea otra cosa que X) (Prelorentzos 1992: 433). En la demostración de la proposición 23, la "cosa" $\mathrm{X}$ es una determinada mente humana; asimismo, aquello que pertenece a su esencia (la característica A) consiste en ser la idea o concepto de la esencia de X, es decir, en expresar objetivamente la esencia de X (según la proposición 22, como vimos, la esencia del determinado cuerpo correspondiente sub specie aeternitatis). De manera que, si aplicamos la definición 2 de la Segunda Parte a esta demostración obtenemos lo siguiente: una mente humana no puede no expresar objetivamente -tal como es en Dios- la esencia del cuerpo del que es idea; e inversamente, una idea o concepto, que está en Dios y expresa la esencia del cuerpo humano sub specie aeternitatis, no puede ser una cosa diferente de la mente humana, al menos en uno de sus aspectos o funciones. ${ }^{10}$ Comprendemos así que la mente humana es la idea de una esencia que se concibe sub specie aeternitatis; pero también

${ }^{10}$ Rousset 1968: 33; Prelorentzos: 1992: 433 ss.; Macherey 1994: 126. 
que tiene una esencia (es una expresión del atributo pensamiento) que debe ser concebida por Dios como una verdad eterna. Es en este sentido entonces que Spinoza dice que a la esencia de la mente humana le pertenece "algo" eterno ( $E \mathrm{~V}, 23$ demostración).

Luego de este rodeo, antes de concluir esta sección volvamos a la pregunta inicial: ¿qué quiere decir qué "algo" de la mente "permanece" cuando el cuerpo del que es la idea desaparece? En este punto, hay que reconocer que Spinoza es un poco ambiguo. En efecto, por un lado, se apoya en $E$ II, 13, que establece una unión o correspondencia estricta entre la mente y el cuerpo. Ahora bien, por otro lado, introduce una distinción entre dos expresiones de esa unión o correspondencia: una en el plano de su existencia actual, otra en el de sus esencias. Podría pensarse entonces que ese "algo" que "permanece" cuando el cuerpo muere lo hace bajo la forma de una sucesión cronológica; o mejor, podría creerse que la esencia de una cosa continúa existiendo una vez que su existencia fue destruida. Sin embargo, es manifiesto que Spinoza no puede significar que la mente sigue existiendo en cuanto que expresa objetivamente un cuerpo que existe en acto, porque si este deja de durar, también la mente lo hace en su existencia actual presente. Ya no podrá ni imaginar ni recordar, ni ser consciente de las afecciones de un cuerpo que ya no es más, porque tampoco habrá una mente (esto es, la idea que existe en acto de un cuerpo) apta para hacerlo. Spinoza es, como vimos, riguroso en este punto: no hay duración de la mente que suceda a su existencia actual, no hay inmortalidad del alma personal. Después de la muerte de Pablo, su mente no existe en un cielo de las formas para adquirir así la salvación eterna. Ya hemos dicho que solo desde la perspectiva de la duración puede pensarse que "algo de ella" permanece "luego" de la muerte. Esa representación de una subsistencia temporal de la esencia de la mente respecto de su existencia debe por lo tanto ser rechazada.

Como hemos visto, desde la perspectiva que resumen las proposiciones 21 a 23, la mente humana es eterna -y le cabe legítimamente ese adjetivo en el mismo sentido que a la sustancia- porque es la idea de una verdad eterna que está en Dios, independiente de cualquier referencia temporal. Es decir, la eternidad de la mente humana se fundamenta aquí en el hecho de que es una idea o concepto que expresa sub specie aeternitatis la esencia del cuerpo. Por lo tanto, como sostiene Matheron, de lo que se trata en este caso, de acuerdo con esta perspectiva, es de la idea eterna que somos (o que Dios tiene de nuestra mente) y no de la idea que nosotros tenemos o que podemos tener (Matheron 2011: 700). Ahora bien, si esto es así, la atribución de la eternidad no solo vale para los seres humanos, pues Dios concibe necesariamente como una verdad eterna todas las cosas que se siguen de su naturaleza infinita. Es cierto que en el enunciado de EV, 23 Spinoza se refiere a la 
mente humana y que en EV, 22 dice que hay una idea en Dios que expresa sub specie aeternitatis la esencia de este o aquel cuerpo humano. No obstante, si tenemos en cuenta las demostraciones que acabamos de comentar y, sobre todo, la ontología que las sustenta, resulta bastante claro que el razonamiento de nuestro autor se fundamenta en un rasgo o propiedad común no solo a todos los cuerpos sino a todas las cosas en general. Por eso, Allison sostiene con razón que esta es una acepción "trivial" de la eternidad de la mente que no se relaciona con lo específicamente humano y que, agreguemos, puede predicarse de cualquier "cosa" (Allison 1987: 170-171). En este sentido, esta eternidad no puede explicar aquello que sin dudas le interesa a Spinoza en la Quinta Parte de la Ética: la salvación que pueden "conquistar" algunos individuos a través del conocimiento. En definitiva, esta perspectiva nos dice solamente que somos eternos pues tenemos una mente que es una idea (de un cuerpo) que está en Dios más allá (o independientemente) de cualquier referencia temporal, es decir, una idea que Dios necesariamente produce autoproduciéndose eternamente. Pero ser una idea eterna no significa tener ideas eternas. Para gozar efectivamente de una eternidad (más o menos) consciente es necesario, de acuerdo con Spinoza, e ntrar en posesión formal de nuestra potencia intrínseca de concebir las cosas sub specie aeternitatis, esto es, devenir causa adecuada del conocimiento verdadero de las cosas tal como son producidas por y en Dios.

\section{La "eternidad para si": el conocimiento sub specie aeternitatis $y$ la salvación humana}

Como mencionamos antes, Spinoza presenta sin embargo la cuestión de la eternidad de la mente desde otra perspectiva, vinculada ya no con el fundamento de la comunicación de esa propiedad a todas las cosas, esto es, con el hecho de que hay en Dios una idea que expresa sub specie aeternitatis su esencia, sino con algo peculiar de la mente humana: el conocimiento adecuado y la alegría que conlleva. Ya no se trata entonces de una eternidad común o universal que se puede predicar tanto de Pablo como de cualquier animal, sino de aquella que en los seres humanos, dotados de un cuerpo y una mente complejas, se relaciona con su salvación, es decir, con su realización ética. Esta perspectiva, que recorre las últimas proposiciones de la Ética, nos explica asimismo que hay diferentes grados de conciencia y conocimiento de nosotros mismos, de las cosas y de Dios, y que, por lo tanto, unas mentes humanas producen efectivamente más ideas adecuadas que otras, por lo que, en ese sentido, participan en mayor medida de la eternidad. Como es evidente, esta aproximación ya no concierne entonces a los seres humanos 
de manera indistinta, sino a algunos de ellos, a quienes probablemente está dirigida la última parte de la Ética, a saber, aquellos que desean y logran (parcialmente) orientar su conatus hacia el conocimiento intuitivo y el amor que de allí resulta y comprenden gracias a ello que la beatitud (entendida como goce eterno de una alegría constante) no es un premio futuro a la virtud sino el ejercicio mismo de una vida virtuosa, aquí y ahora. Veamos brevemente como se desarrolla esta perspectiva en el texto.

Antes dijimos que hay que rechazar la representación de la eternidad de la mente en los términos de una sucesión cronológica, como si la esencia eterna comenzara a existir luego de la existencia temporal misma. Por los mismos motivos también hay que rechazar que, para Spinoza, la mente humana pueda tener en sí misma porciones absolutamente independientes. O mejor dicho, debemos rechazar que ese "algo de ella" que según Spinoza es eterno (ejus aliquid remanet, quod aeternum est) es una parte que constituiría la esencia de la mente en oposición -o como una parte separada- a su existencia actual. Como señalan de diversa manera Macherey y Rousset, esto significa que la esencia no es una "parte" o un ser distinto de la existencia de una cosa; la esencia y la existencia de una cosa no se diferencian como lo hacen por ejemplo dos cuerpos, partes extra partes. Son dos aspectos del mismo modo (sea un cuerpo o una idea). ${ }^{11}$ Recordemos de hecho que en la demostración de la proposición 23 nuestro autor no dice que la mente humana es eterna, sino que "algo" que pertenece a su esencia es "necesariamente eterno" $(E$ V, 23 demostración). Ahora bien, si, como vimos, esa eternidad no es una inmortalidad del alma, si esa propiedad no pertenece irrestrictamente a la existencia actual presente de los modos o a su esencia como si esta fuera una parte separable y distinta de su existencia concreta, ¿qué es lo eterno en ciertos modos finitos, y más precisamente en los seres humanos? ¿Cómo debemos comprender la expresión del corolario de la proposición 40 donde Spinoza sostiene que "la parte de la mente que permanece, cualquiera sea su magnitud, es más perfecta que la restante" ( $E \mathrm{~V}, 40$ corolario)?

Tanto la demostración como el escolio de la proposición 23 nos ofrecen ya algunos indicios importantes. Por un lado, en la primera Spinoza refiere a ese "algo" como una "idea o concepto" (EV, 23 demostración). Para un lector de la Ética, esos términos remiten necesariamente a la definición que aparece al inicio de la Segunda Parte, en la que se identifica la idea con la acción de la mente:

${ }^{11}$ Rousset 1968: 45; Macherey 1994: 129-130. 
Por idea entiendo el concepto de la mente, que la mente forma, porque es cosa pensante. Explicación. Digo concepto, más bien que percepción, porque el nombre percepción parece indicar que la mente es pasiva respecto del objeto; concepto, en cambio, parece expresar una acción de la mente. (E II, definición 3)

Por otro lado, y en el mismo sentido, en el escolio Spinoza dice que la idea que expresa la esencia del cuerpo sub specie aeternitatis es un "modo del pensar" (certus cogitandi modus) que pertenece a la esencia de la mente y es necesariamente eterno ( $E \mathrm{~V}, 23$ escolio). Como señala Rousset, con esa expresión el filósofo holandés reenvía a una cuestión relativa a la "naturaleza" de la idea verdadera sobre la que había insistido al momento de elaborar su teoría del conocimiento (Rousset 1968: 34). En efecto, Spinoza sostiene que

[...] tener una idea verdadera no significa sino que se conoce una cosa perfectamente o lo mejor posible. Y nadie en absoluto puede dudar de ello, a menos que piense que una idea es algo mudo, cual pintura en una tabla, y no un modo del pensar, a saber, el mismo entender. ( $E$ II, 43 escolio)

Hay como vemos una doble equivalencia: entre la idea y la acción de la mente, por un lado, y entre esta última y el entendimiento de las cosas de manera adecuada o verdadera, por el otro. Estos pasajes nos permiten concluir entonces que aquello que Spinoza considera eterno, esto es, la idea o concepto que pertenece a la esencia de la mente humana, es el acto de concebir en tanto que constituye una de sus funciones; es decir, en tanto la mente se define íntima y positivamente por una actividad irreductible a la imaginación y a la memoria. En otras palabras, se trata de una aptitud o capacidad intrínseca, una potencia de conocer que expresa una acción de la mente. ${ }^{12}$ Nuestro autor no dice otra cosa cuando vincula en el escolio de $E$ V,23 la experiencia de la eternidad con la concepción que la mente humana puede tener de las cosas a partir de su "inteligencia": "[...] sentimos y experimentamos que nosotros somos eternos. Pues la mente no siente menos las cosas que concibe con la inteligencia que las que tiene en la memoria" ( $E$ V, 23 escolio).

Ahora bien, ¿qué tipo de conocimiento es este? Como vimos, la principal característica de esta capacidad o modalidad de conocimiento es que aprehende su objeto (la esencia del cuerpo) sub specie aeternitatis, esto es,

${ }^{12}$ Rousset 1968: 35; Allison 1987: 171 ss.; Macherey 1994: 128; Jaquet 1997: 109-123. 
independientemente de cualquier referencia temporal. Si solo tuviésemos en cuenta las proposiciones que siguen al escolio mencionado, podríamos llegar a pensar que se trata únicamente del tercer género de conocimiento, el cual, como dice Spinoza, constituye el supremo esfuerzo de la mente y su máxima virtud $(E \mathrm{~V}, 25)$. No obstante, basta con detenerse en ciertos pasajes de la Segunda y la Quinta Parte de la Ética para comprender que alcanza también al segundo género de conocimiento. Consideremos por ejemplo la proposición 44 del De origine et natura mentis. Allí se dice que pertenece a la naturaleza de la razón contemplar las cosas como necesarias y no como contingentes ( $E$ II, 44). Luego de desarrollar la forma en que la imaginación percibe los objetos externos (a saber, como situados en un contexto espacio-temporal y localizados en el tiempo), nuestro autor afirma en el segundo corolario que es "propio de la naturaleza de la razón percibir las cosas bajo alguna especie de eternidad (sub quadam specie aeternitatis)" (E II, 44 corolario 2). La prueba es sencilla: remitiendo a la proposición 16 de la primera parte, Spinoza dice que, puesto que la necesidad de las cosas "es la misma necesidad de la naturaleza eterna de Dios" "es propio de la naturaleza de la razón contemplar las cosas bajo esta especie de eternidad (sub hac specie aeternitatis)" (E II, 44 corolario 2).

Por cierto, Spinoza no deja de aclarar allí que las nociones comunes, fundamento de la razón, explican solo aquello que es común a todas las cosas y no la esencia de una (o alguna) cosa singular. Podría objetarse entonces el carácter eterno del conocimiento de segundo género, apelando a la expresión precisa que utiliza nuestro autor para describir lo que es propio de la razón. En este sentido, los términos quadam ("alguna", "una") y hac ("esta") servirían para establecer una diferencia estricta entre el segundo y el tercer género de conocimiento.Y solo la ciencia intuitiva conocería en su necesidad eterna las cosas. Sin embargo, antes de sacar conclusiones apresuradas conviene tener presente al menos tres elementos adicionales. Para empezar, no hay que olvidar que Spinoza reenvía a $E$ II, 41, en donde afirma de manera explícita que las ideas adecuadas pertenecen tanto al segundo como al tercer género de conocimiento ( $E$ II, 44 demostración y demostración del corolario). Pero sobre todo, hay que notar que el conocimiento sub quadam specie aeternitatis cumple con la exigencia de la concepción sub specie aeternitatis, establecida en EV, 29 escolio. Allí, como sabemos, para precisar la irreductibilidad de esta concepción respecto de todo lo que la mente conoce en función de la existencia actual del cuerpo humano, el filósofo holandés sostiene que para formarla es necesario comprender de manera verdadera que las cosas están contenidas en Dios, que se siguen de su naturaleza y que sus ideas implican la esencia eterna e infinita (EV, 29 escolio). Ahora bien, esto vale también para lo que Spinoza sostiene del conocimiento racional 
en el corolario de la proposición 44 de la Segunda Parte. En efecto, como mencionamos, la razón aprehende con verdad la necesidad de las cosas, tal como son en sí, y vincula esa necesidad a la naturaleza eterna de Dios. Es cierto que Spinoza no dice allí de manera explícita que para la razón las cosas están contenidas en Dios y que implican su esencia. Pero el escolio de E II, 45 , sin embargo, lo establece con toda evidencia y recuerda además que la "existencia" de las cosas (concebidas de esa forma) no es la duración actual sino la existencia o ser de las cosas en tanto son en Dios (E II, 45 escolio). Por último, agreguemos a todo esto que en la demostración de EV, 29, que reenvía precisamente al corolario de $E$ II, 44, el filósofo holandés asimila el conocimiento racional sub quadam specie aeternitatis de ese corolario con la concepción sub specie aeternitatis:

[...] la eternidad no se puede explicar por la duración (por $1 / \mathrm{d} 8$ y su explicación). Luego, en este sentido, la mente no tiene la potestad de concebir las cosas sub specie aeternitatis, sino porque por naturaleza es propio de la razón concebir las cosas sub specie aeternitatis (por 2/44c) y porque también pertenece a la naturaleza de la razón concebir la esencia del cuerpo sub specie aeternitatis (por 5/23). (EV, 29 demostración)

Podemos concluir entonces que, de acuerdo con Spinoza, la razón es capaz de comprender las cosas tanto sub quadam specie aeternitatis como sub specie aeternitatis. En este sentido, no es legítimo apelar a la primera expresión para establecer una discriminación entre el segundo y el tercer género de conocimiento (Jaquet 1997: 120-121). En ambos casos -ya sea que las conciba a partir de las nociones comunes, ya sea que forme la idea adecuada de su esencia singular- la mente humana "entiende" o concibe las cosas como absolutamente necesarias y eternas, independientemente del modo como nos afectan. El término “quadam”, entonces, no tiene otro propósito que reenviar al punto de vista particular (de la razón) en el que las cosas son conocidas a partir de las propiedades comunes, lo cual no compromete el valor adecuado de la concepción, puesto que las propiedades y la esencia del cuerpo son ambas verdades eternas (Matheron 1969: 579).

Si hay una distinción importante, entonces, es la que se da entre las ideas inadecuadas (que nos presentan las cosas y nuestros propios afectos fortuitamente y en función de las afecciones discontinuas del cuerpo) y las ideas adecuadas del entendimiento, que nos permiten conocer las cosas y aquello que nos sucede en su necesidad y verdad, ya sea a partir de las propiedades comunes de nuestro cuerpo, o bien a partir de su esencia. La proposición 29, su demostración y el célebre escolio que las acompaña, apuntan precisamente a esto. Allí Spinoza sostiene por un lado que a la esencia de la mente 
(que es siempre idea de un cuerpo según E II, 13) le pertenecen solo dos maneras de concebir su cuerpo y las cosas exteriores: o bien sub specie aeternitatis, o bien sub specie durationis (EV, 29 escolio). Es decir, por su propia naturaleza, la mente humana tiene dos maneras de conocer, una que depende de la concepción eterna de la esencia de su cuerpo y de las cosas, y otra que depende de su existencia actual presente. La primera incluye al segundo y tercer género de conocimiento, siendo su rasgo principal aprehender tanto la esencia del cuerpo como la de las cosas, en sí mismas o a partir de sus propiedades, pero siempre como necesarias, nunca como contingentes y fortuitas, pues esta es la característica principal de la percepción del primer género de conocimiento, esto es, de la imaginación y de la relación espontánea del ser humano con su entorno que aquella implica.

Es cierto que Spinoza subraya en el escolio que en la concepción sub specie aeternitatis las cosas no dejan de concebirse o conocerse como "actuales" (no hay espacio en el spinozismo para lo posible como instancia opuesta o previa a lo actual). Pero su actualidad no corresponde a aquella que depende de una dimensión espacio-temporal ( $E V, 29$ escolio). La referencia en ese escolio a $E$ II 45 y a su escolio, que nuestro autor coloca deliberadamente al final de este razonamiento, echan todavía más luz al asunto. Allí, como ya señalamos, el filósofo holandés distingue la duración y la "existencia misma de las cosas singulares en cuanto son en Dios (ipsa existentia rerum singularium, quatenus in Deo sunt)" (E II, 45 escolio). Con esa alusión, entonces, Spinoza no quiere decir que, en la medida en que concebimos la realidad actual de nuestro cuerpo y de las cosas sub specie aeternitatis, estas dejan de existir temporalmente; al contrario, apunta a subrayar el hecho de que, a través de ese conocimiento, comprendemos que no existen solamente en relación con el modo como nos afectan sino también, y sobre todo, "en Dios", esto es, como expresiones necesarias de la potencia infinita. Porque, como dice nuestro autor en ese escolio, más allá de que las cosas finitas estén determinadas por otras cosas finitas desde el exterior, partes extra partes, "la fuerza $[. .$.$] con que cada una persevera en la existencia se sigue de la nece-$ sidad eterna de Dios" (E II 45, escolio). Spinoza reitera este mismo punto un poco más adelante, al precisar de manera exacta el conocimiento que los seres humanos pueden tener:

La eternidad es la misma esencia de Dios, en cuanto que esta implica la existencia necesaria (por E I, definición 8). Concebir, pues, las cosas sub specie aeternitatis es concebir las cosas, en cuanto que se conciben como seres reales por la esencia de Dios, o sea, en cuanto que por la esencia de Dios implican la existencia. ( $E V, 30$ demostración) 
Este pasaje debe interpretarse del siguiente modo: Dios, o el ser absolutamente infinito, comunica a las cosas finitas la existencia necesaria, y por eso su realidad no está sujeta a la contingencia. Por lo tanto, cuando esas cosas (que tienen una existencia actual presente y pueden durar más o menos) se conciben a partir de la esencia divina, que es su causa inmanente, la realidad de esas cosas (siempre efectos de la potencia infinita) deja de ser considerada en relación con la duración o el tiempo. Por el mismo motivo, entonces, "en la medida en que nuestra mente se conoce a sí misma y al cuerpo sub specie aeternitatis, tiene necesariamente el conocimiento de Dios y sabe que ella está en Dios y se concibe por Dios" (EV, 30). En definitiva, la mente se sabe eterna en el reconocimiento de su propia potencia de concebir las cosas como efectos inmanentes y eternos de Dios. Sabe que es una cosa que está intrínsecamente constituida por una aptitud irreductible a la imaginación. Es decir, para decirlo de otra forma, en el conocimiento sub specie aeternitatis, la mente humana sabe que participa de la eternidad divina, con la cual se relaciona directamente por vía del conocimiento adecuado. El razonamiento culmina por eso con la explicación de que la mente humana, que concibe las cosas y su cuerpo (del que es la idea) como eternos y atemporales, es ella misma eterna (mens ipsa aeterna est) $(E \mathrm{~V}, 31)$. Ella no solo dispone de la capacidad o aptitud de conocer las cosas sub specie aeternitatis, también se afirma a sí misma como "causa adecuada o formal de ese conocimiento" (E V, 31 demostración). De hecho, si no fuera eterna una "parte" suya, o mejor dicho, en uno de sus aspectos constitutivos, jamás podría concebir las cosas de ese modo. ${ }^{13}$

La mente, dijimos, se sabe eterna en el reconocimiento de su propia potencia. Ahora bien, aquí podría presentarse un problema. Como vimos, Spinoza sugiere que en un momento determinado de su existencia actual, la mente descubre (o puede descubrir) su aspecto o ser eterno al mismo tiempo que comprende la eternidad de Dios y la de la concepción necesaria de las cosas (entre las que se cuenta a sí misma). ¿Acaso no es problemático sostener que la mente reconoce en el curso de su existencia un aspecto suyo que es eterno, esto es, intemporal? Es decir, el camino que conduce en las últimas proposiciones de la Ética a la conciencia y conocimiento de la eternidad, ¿no anula aquello que le da contenido y sentido a ese movimiento progresivo de la mente? Spinoza no ignora el problema y por el contrario lo afronta directamente en el escolio de EV, 31:

${ }^{13}$ Matheron 1969: 580 y 2011: 704; Prelorentzos 1992: 484; Jaquet 1997: 109. 
[...] hay que observar aquí que, aunque ya estamos seguros de que la mente es eterna, en cuanto que concibe las cosas sub specie aeternitatis, nosotros, $\sin$ embargo, a fin de explicar más fácilmente lo que queremos mostrar y que se lo entienda mejor, consideraremos la mente, como hemos hecho hasta ahora, como si ya comenzara a existir y ya comenzara a entender las cosas sub specie aeternitatis. (EV, 31 escolio)

El conocimiento reflexivo, que obtenemos en un momento determinado, de que la mente es eterna (es decir, la idea de la idea eterna que es nuestra mente) no está puesto en duda por el desarrollo tendencial y progresivo con que esta certeza es adquirida por un individuo. Siempre que entendemos adecuadamente las cosas emerge su carácter necesario, su eternidad. Se trata entonces, como reconoce Spinoza mismo, de una forma de presentar su doctrina que permite comprender "más fácilmente" un rasgo central que la caracteriza, a saber, que la conciencia de la eternidad está a nuestro alcance y no en un cielo de las formas que la tornaría inaccesible (Macherey 1994: 151). Esto supone que el conocimiento del tercer género es en sí mismo eterno, pero que es en la duración (o mientras tenemos una existencia actual presente) que tomamos (o que podemos tomar) conciencia, poco a poco, de esa eternidad, en otras palabras, que podemos experimentar que somos eternos. ${ }^{14}$ Es cierto que no es "por" la duración que conocemos las cosas como eternas; es decir, no es porque concebimos la existencia actual presente de nuestro cuerpo que podemos comprender adecuadamente la eternidad de una parte de la mente y el modo como las cosas se siguen de la esencia divina. Para percibir la mente y las cosas de esa forma es necesario, como vimos, que concibamos la esencia del cuerpo sub specie aeternitatis ( $E$ V, 29 y escolio). Lo cual da nacimiento a una conciencia que no es más de orden temporal. Ahora bien, eso no quita que para que un individuo, en algún momento de su historia personal o progresivamente, devenga consciente de la eternidad de su entendimiento y de las cosas, deba tener una existencia actual presente. En caso contrario, ¿qué sentido podría tener el rechazo de Spinoza de presentar la doctrina de la eternidad en los términos de una inmortalidad y, sobre todo, la profunda conexión que existe para nuestro autor entre esa doctrina y la ética de la salvación o liberación humana?

\footnotetext{
${ }^{14}$ Véase Matheron 1969: 582: “[...] la parte eterna de nuestro espíritu aumentará en el curso del tiempo, a medida que se develen los aspectos cada vez más individualizados de nuestra esencia". Véase también: Rousset 1968: 40: "Por más que la expresión sea paradójica, es preciso reconocer que la idea de un progreso de la parte eterna del espíritu implica la afirmación de su eternidad progresiva: así se encuentra definido el sentido de nuestra vida [...]"
} 
Precisamente porque lo que está en juego es la virtud, el pensamiento spinoziano se consagra, para finalizar, a una reflexión que considera el problema de la eternidad de la mente desde una perspectiva específicamente ética, vinculada con la salvación humana. En efecto, más allá del carácter eterno que pueda tener la concepción del segundo género de conocimiento y de la existencia de un pasaje al tercero (cuya naturaleza acabamos de mencionar), hay que tener presente que lo que quiere subrayar Spinoza en la Quinta Parte de la Ética es el vínculo de este último género de conocimiento con la beatitud y con la perfección humana. De hecho, como ya afirma en el Prefacio de la Segunda Parte, su interés principal son los seres humanos y aquello que puede conducirlos hacia su perfección:

Paso ya a explicar las cosas que debieron seguirse necesariamente de la esencia de Dios, a saber, del ser eterno e infinito. No todas, sin duda, ya que en 1/16 hemos demostrado que de ella debieron seguirse infinitas cosas en infinitos modos, sino tan solo aquellas que nos pueden llevar como de la mano al conocimiento de la mente humana y de su felicidad suprema. (E II, Prefacio)

Si tenemos en cuenta ese pasaje, resulta claro que las últimas proposiciones de la Ética no consideran solamente la identificación de la capacidad de la mente de conocerse a sí misma y a las cosas sub specie aeternitatis (a través de la llamada ciencia intuitiva) con su propia eternidad (EV, 24-31). También explican el lazo de esa mente con la perfección y beatitud a las que puede acceder el ser humano en la medida en que el tercer género de conocimiento va acompañado del amor intelectual de Dios (EV, 32-38). Esto ciertamente ya había sido sugerido por el filósofo holandés antes, en las proposiciones que estudian los remedios de los afectos. Sobre todo en el escolio de la proposición que cierra la primera sección de la Quinta Parte, donde nuestro autor explica que la mente tiene, a través del tercer género de conocimiento, la potestad de hacer que se padezca menos por los afectos negativos, pudiendo nacer en consecuencia el "amor a Dios", amor erga Deum. En aquel momento de la deducción, ese amor y el conocimiento del que surge aparecían como instrumentos o fuerzas en la lucha contra las pasiones tristes; precisamente por eso se los consideraba en su aspecto, por así decir, "terrenal" o temporal (EV, 20 escolio). Ahora, en esta segunda sección del De potentia intellectus seu de Libertate humana-que no concierne a la "vida presente"-, Spinoza estudia ese mismo amor eterno con la intención de mostrar que constituye la beatitud humana y la suma perfección a la que puede aspirar un individuo (Allison 1987: 164). No se trata entonces de una simple alegría, entendida como el paso a una mayor perfección, sino de "la mayor alegría que puede 
darse", aquella que está acompañada de la idea de Dios como causa y que escapa a cualquier determinación temporal $(E V, 32)$. En este sentido, este amor intelectual (amor Dei intellectualis) es, lo mismo que el conocimiento del que surge, necesariamente eterno $(E \mathrm{~V}, 33)$. Así, quien lo conquista, por lo tanto, "está en posesión de la perfección misma" y es eternamente "feliz" ( $E \mathrm{~V}, 33$ escolio).

Como vemos, es en este momento del discurso que el "quien" se vuelve importante. En efecto, para terminar con su argumentación Spinoza agrega algo cardinal, relativo al carácter diferencial de esta eternidad. Para comenzar, en $E \mathrm{~V}, 38$ dice que cuantas más cosas entiende la mente humana con el segundo y el tercer género de conocimiento, menos padece por los afectos que son malos y menos teme a la muerte $(E V, 38)$. Dicho de otra forma, esto significa que cuantas más ideas adecuadas tiene una mente (cuya esencia "consiste en el conocimiento"), tanto más participa de la eternidad en esta vida; en otras palabras, como dice nuestro autor en la demostración correspondiente con cierta ambigüedad, "la mayor parte de ella permanece", pues no es "tocada por los afectos que son contrarios" a su naturaleza ( $E V, 38$ demostración). Insistamos en algo que ya dijimos: nuestro autor no está afirmando una inmortalidad personal; simplemente está diciendo que cuanto mayor es el conocimiento eterno y adecuado de la mente, "la muerte es tanto menos nociva", es decir, ocupa (en términos de importancia) una porción mínima de su esfuerzo por perseverar en la existencia ( $E \mathrm{~V}, 38$ escolio).

Ahora bien, como es evidente, esto significa asimismo que esta "eternidad parcial", para retomar una expresión de Rousset, puede ser más o menos desarrollada en los seres humanos (Rousset 1968: 37). En palabras de Spinoza: "Quien tiene un cuerpo apto para muchísimas cosas, tiene una mente cuya mayor parte es eterna" $(E V, 39)$. La experiencia muestra esto con mucha claridad. Ciertamente, en todos hay al menos una idea verdadera, del mismo modo que a la esencia de todas las mentes pertenece sin dudas "algo" eterno. Sin embargo, esto no significa que no haya diferencias y que no puedan juzgarse, como hace Spinoza, los grados de participación individual de la eternidad divina en términos de la virtud personal. Pues como sostiene él mismo en la última proposición de la Ética, la felicidad (beatitudo) no es un premio de la virtud que ha de esperarse sino el mismo ejercicio de la virtud $(E \mathrm{~V}, 42)$. A través de las intrincadas y complejas proposiciones finales de la obra póstuma somos así reconducidos a la duración, esto es, a la existencia actual presente, sin que ello entre en contradicción con lo anterior. 


\section{Conclusión}

Z1 recorrido que hemos realizado, siguiendo la misma lógica ar-

gumentativa de Spinoza, nos permite comprender tres cosas. Por un lado, que para Spinoza aquello que es eterno en los seres humanos es sobre todo un conocimiento, una idea que forma parte de la esencia de su mente, que se concibe a sí misma como causa formal del mismo y es en ese sentido eterna. En otras palabras, lo eterno es el entendimiento en la medida en que es causa adecuada de sus ideas eternas, ya sea en cuanto estas se forman a partir de las propiedades comunes de las cosas, o bien en cuanto que determinan su esencia singular. Por otro lado, comprendemos también que esa eternidad consiste en una actividad inmanente y liberadora de la mente, que puede procurar la salvación (beatitud, felicidad, libertad) de seres cuyo esfuerzo es siempre perseverar en la existencia. Con lo cual, reencontramos aquí ciertos rasgos que caracterizan a la acción divina, esto es, a la potencia infinita en la Primera Parte de la Ética. Como sabemos, para Spinoza esa acción causal es eterna y necesariamente libre, causa sui. Si bien es cierto que los modos no pueden dejar de ser modos y nunca son causa de sí, en el esfuerzo que define intrínsecamente su mente identificamos una actividad inmanente y necesaria que no solo es eterna (pues se basa en una concepción sub specie aeternitatis de su cuerpo y de las cosas) sino también liberadora, en la medida en que expresa la autodeterminación del modo, es decir, la autodeterminación de la fuerza singular e intrínseca que lo atraviesa y constituye eternamente. Ciertamente, para Spinoza esta salvación es muy dificil y no puede ser alcanzada sin un gran esfuerzo. Por eso, aunque no niega nunca que podamos tener (o que algunos puedan tener) esa aprehensión de las cosas y de la propia vida, la Ética se cierra con una constatación drástica: "Todo lo excelso es tan raro como difícil" (Omnia praeclara tam difficilia quam rara sunt) (EV, 42 escolio).

Finalmente, comprendemos un rasgo particular de la concepción spinoziana de la eternidad, tal como es expuesta en la obra póstuma o, para ser precisos, del problema que supone la atribución de esa propiedad a las cosas particulares en el marco de su ontología de la inmanencia. Ya sea que la concibamos como una noción común de la que se puede ser más o menos consciente o como una propiedad inmanente que pertenece a la esencia de la mente humana y expresa sub specie aeternitatis la esencia del cuerpo, la conclusión es siempre la misma: a diferencia de lo que sostenía en los Pensamientos metafísicos, en esta obra madura Spinoza no atribuye exclusivamente la eternidad a Dios, sino que la extiende legítimamente a otras realidades que son sus efectos inmanentes y que dependen de una determinación que, en cierta medida (esto es, parcialmente), escapa de los condicionamientos 
externos. Por lo tanto, la enseñanza más importante de la parte final de esta obra quizá sea esta: no hay que justificar ninguna inmortalidad del alma frente a la tradición; los seres humanos son -aquí y ahora, aunque en mayor o menor medida- eternos, puesto que sus mentes tienen efectivamente ideas adecuadas que expresan sub specie aeternitatis la esencia del cuerpo y las de las cosas exteriores. Es decir, en otras palabras, los seres humanos (o mejor: algunos de ellos) pueden eventualmente concebir las cosas tal como son producidas en y por Dios. Pero si pueden hacerlo es precisamente porque "algo" de ellos es también eterno: su entendimiento adecuado activo, expresión de la potencia intrínseca de la mente de un ser que se esfuerza siempre cuanto puede por perseverar en la existencia.

\section{BIBLIOGRAFÍA}

Allison, H. E. (1987), Benedict de Spinoza: an Introduction (New Haven:Yale University Press).

Jaquet, C. (1997), Sub specie aeternitatis: étude des concepts de temps, durée et éternité chez Spinoza (París: Kimé).

Macherey, P. (1994), Introduction à l'Ethique de Spinoza, la cinquième partie: les voies de la libération (París: PUF).

Matheron, A. (1969), Individu et communauté chez Spinoza (París: Éditions de Minuit).

Matheron, A. (2011), Études sur Spinoza et les philosophies de l'âge classique (Lyon: ENS).

Prelorentzos, Y. (1992), La durée chez Spinoza, tesis de doctorado, Université Paris-Sorbonne.

Prelorentzos, Y. (1996), Temps, durée et éternité dans les Principes de la philosophie de Descartes de Spinoza (París: PUF).

Rousset, B. (1968), La perspective finale de l'Ethique et le problème de la cohérence du spinozisme: l'autonomie comme salut (París:Vrin).

Rousset, B. (2000), L'immanence et le salut: regards spinozistes (París: Kimé).

Spinoza, B. (CM), Pensamientos metafísicos, introducción, traducción y notas de A. Domínguez (Madrid: Alianza, 1988).

Spinoza, B. (E), Ética, introducción, traducción y notas de A. Domínguez (Madrid: Trotta, 2000).

Spinoza, B. $(K V)$, Tratado breve, introducción, traducción y notas de A. Domínguez (Madrid: Alianza, 1990).

Spinoza, B. (TIE), Tratado de la reforma del entendimiento: principios de la filosofía de Descartes, traducción de A. Domínguez (Madrid: Alianza, 1988).

Spinoza, B. (TP), Tratado político, traducción de A. Domínguez (Madrid: Alianza, 1986).

Spinoza, B. (TTP), Tratado teológico-político, introducción, traducción y notas de A. Domínguez (Madrid: Alianza, 1986). 
Spinoza, B. (1925), Opera, editada por C. Gebhardt (Heidelberg: C. Winter).

Wolfson, H. A. (1934), The Philosophy of Spinoza: Unfolding the Latent Processes of his Reasoning, 2 vols. (Cambridge: Harvard University Press).

Recibido: 26-09-2018; aceptado: 06-05-2019 